\title{
ANALISA FAKTOR-FAKTOR PENYEBAB KETERLAMBATAN PROYEK PEMBANGUNAN GEDUNG UVERS
}

\author{
Fuad Dwi Hanggara ${ }^{1)}$ \\ Fakultas Teknik, Universitas Universal \\ e-mail: samfu.31@gmail.com
}

\begin{abstract}
Abstrak
Abstrak : Kebutuhan masyarakat akan pendidikan, kebutuhan tersebut juga diiringi dengan banyaknya tuntutan dan tuntutan pekerjaan sehingga setiap lulusan harus memiliki kompetensi yang kompetitif. Hal ini mendorong berdirinya Universal University untuk menampung lulusan SMA dan SMK untuk melanjutkan pendidikan. Pembangunan Universitas dimulai pada tahun 2013. Proses pembangunan bisa dikatakan terlambat karena sudah dalam pengerjaan selama 7 tahun namun perkembangannya bisa dikatakan cukup lambat. Penelitian ini mengidentifikasi faktor-faktor yang mempengaruhi keterlambatan pengembangan UVERS. Dalam penelitian ini diterapkan metode diagram Fishbone sehingga dapat mengkategorikan faktor-faktor yang mempengaruhi keterlambatan. Salah satu faktor yang paling berpengaruh dalam keterlambatan pembangunan adalah dari segi sumber daya manusia, karena banyak tenaga kerja yang tidak memiliki keterampilan yang sesuai dengan pekerjaan yang dilakukan. Sebelum mengontrak proyek, harus ada proses pengenalan anggota vendor proyek sehingga mereka dapat memahami kapabilitas pekerja sebelum membuat perjanjian kontrak dengan vendor.
\end{abstract}

Kata Kunci: Diagram Fishbone, Keterlambatan, Proyek

\begin{abstract}
Community needs for education, these needs are also accompanied by many requirements and work demands so that each graduate must have competitive competence. This encourages the establishment of Universal University to accommodate high school and vocational graduates to continue their education. The construction of the University began in 2013. The development process can be said to be late because it has been under construction for 7 years but the progress can be said to be quite slow. This research identifies the factors that influence the delay of UVERS development. In this research the Fishbone diagram method is applied so that it can categorize the factors that influence delays. One of the most influential factors in development delays is in terms of human resources, because many workers do not have the skills appropriate to the work performed. Before contracting the project, there should be a process of introducing members of the project vendor so that they can understand the capabilities of the workers before entering into a contractual agreement with the vendor.
\end{abstract}

Keywords: Fishbone Diagram, Lateness, Project

\section{PENDAHULUAN}

Kebutuhan masyarakat akan melanjutkan pendidikan ke perguruan tinggi semakin meningkat, terutama bagi tamatan pendidikan sekolah menengah atas yang ingin melanjutkan ke perguruan tinggi. Kebutuhan tersebut juga diiringi dengan banyaknya persyaratan dan tuntutan kerja agar setiap lulusan harus memiliki kompetensi yang bersaing. Halhal tersebut merangsang lembaga pendidikan untuk membuat wadah pembelajaran untuk adanya peningkatan mutu pendidikan selain daripada lulusan, sektor sarana prasarana yang memadai seperti bangunan yang aman dan nyaman, laboratorium, fasilitas penunjang, dan kapabilitas dosen dan tenaga pendidik 
(Yusuf, 2014). Dan dalam hal ini yang dalam pelaksanaan pembangunan adalah Gedung Universitas Universal Batam (UVERS). Pembangunan gedung UVERS ini adalah gedung utama dari perguruan tinggi ini. Sebelumnya sebelum gedung tersebut di bangun, UVERS sudah berizin dan beroperasi dari tahun 2015 dan masih menempati bangunan SMA Maitri.

Proyek gedung UVERS ini adalah salah satu pembangunan yang kemungkinan akan memunculkan risiko bagi proyek tersebut maupun lingkungan sekitarnya, proyek pembangunan ini memakan waktu yang cukup lama dalam pengurusan perizinan, baik itu perizinan pada pemerintah dan juga dinas lingkungan yang bersangkutan. Risiko yang muncul tersebut dapat menjadi halangan bagi kelancaran pembangunan gedung UVERS. Oleh karena itu diperlukan langkah pencegahan yang sesuai dengan risiko yang menjadi permasalahan pada proyek gedung UVERS. Penelitian ini bertujuan untuk melakukan analisis risiko Proyek Pembangunan UVERS yang bertempat di Kawasan pasir Putih Batam Center.

Analisis dimulai dengan identifikasi risiko yang dilakukan dengan menggunakan tools Fishbone diagram. Setelah itu mencari kemungkinan risiko yang akan terjadi. Langkah yang terakhir adalah memberikan usulan pencegahan risiko dimana dapat mengurangi ataupun menghilangkan dampak dari risiko yang nantinya akan terjadi (Nilma, 2018). Dengan berbagai faktor-faktor penyebab keterlambatan yang telah di dapatkan dari penelitian ini, diharapkan dapat membantu pembangunan proyek untuk menurunkan angka keterlambatan. Kemudian juga dapat mencari solusi untuk menyelesaikan permasalahan keterlambatan tersebut.

\section{METODE PENELITIAN Desain Penelitian}

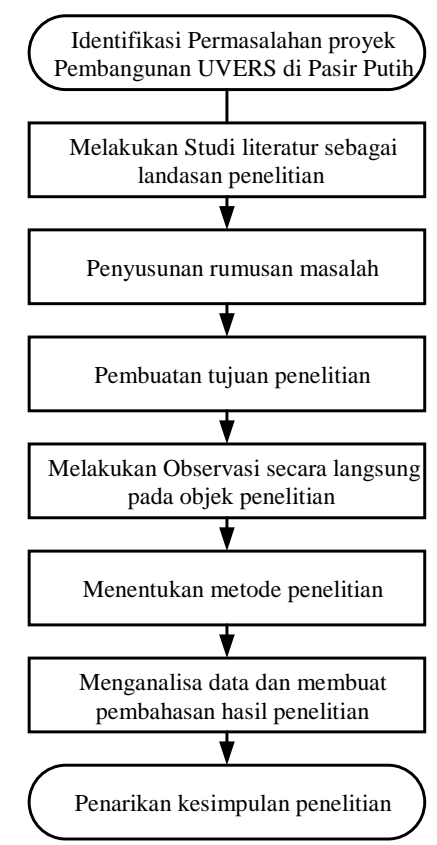

Gambar 1. Flowchart Penelitian

Bentuk penelitian ini dimulai dengan melakukan identifikasi permasalahan dalam proyek pembangunan UVERS yang ditempatkan pada lokasi Pasir Putih, Kota Batam. Hal ini dilakukan bertujuan untuk memastikan bahwa adanya masalah yang mempengaruhi keterlambatan proses proyek berlangsung. Kemudian juga akan melakukan studi literatur untuk dijadikan sebagai dasar teori dalam penelitian ini. Setelah mengetahui permasalahan dari proyek maka perlu menyusun rumusan masalah dan tujuan dalam penelitian ini sehingga hasil dari penelitian ini akan terlihat lebih spesifik.

Selanjutnya adalah melakukan pengumpulan data dengan cara observasi sehingga bisa mendapatkan data secara langsung dan di analisis sesuai dengan metode yang telah ditentukan. Kemudian melakukan pembahasan dari hasil analisa yang telah dilakukan untuk memperjelas hasil analisisnya. Yang terakhir adalah menarik kesimpulan dari penelitian yang telah dilakukan, hasil dari penelitian 
harus menjawab rumusan masalah sehingga tujuan dari penelitian dapat tercapai.

\section{Teknik Pengumpulan Data}

Menurut (Sugiyono,2012) populasi adalah wilayah generalisasi yang terdiri atas obyek atau subyek yang mempunyai kualitas dan karakteristik tertentu yang diterapkan oleh peneliti untuk dipelajari dan kemudian ditarik kesimpulannya. Populasi dalam penelitian yang digunakan adalah stakeholder dan tukang yang terlibat dalam proyek pembangunan.

Sampel adalah sebagian dari jumlah dan karakteristik yang dimiliki oleh populasi (Sugiyono, 2012). Dalam penelitian ini teknik pengambilan sampel yang dilakukan adalah purposive sampling. Hal ini dilakukan dengan pertimbangan dikarenakan keterbatasan waktu, tenaga, dan dana. Serta kuisioner ini diberikan hanya kepada top management (supervisor, ketua yayasan, kepala proyek). Dan pada tahap akhir akan dilakukan brainstorming untuk menyaring hasil dari kuisioner serta mendapatkan hasil alternatif jawaban yang terbaik.

\section{Pengolahan Data}

Setelah memperoleh data primer maupun data sekunder, teknik pengolahan data dan analisis data yang digunakan adalah dengan menggunakan metode Fishbone diagram. Sehingga dapat menggambarkan penyebab keterlambatan proyek pembangunan UVERS di Pasir Putih. Selain metode Fishbone, data yang didapatkan akan di susun dalam tabel dan diagram batang untuk melihat perbandingan faktor-faktor penyebab keterlambatan proyek.
Selain itu, respon dari hasil kuesioner juga akan diolah dengan aplikasi SPSS untuk mengetahui apakah ada pengaruh antara faktor-faktor penyebab dengan dampak keterlambatan proyek. Berikut ini adalah daftar pertanyaan yang akan diwawancarakan kepada pemilik yayasan, ketua pembangunan, pengawas pembangunan dan buruh. Pada tahap sebelumnya dilakukan tahap focus group discussion (FGD) dengan beberapa pihak stakeholder yang terlibat dalam proyek pembangunan gedung agar pertanyaan menjadi valid.

Tabel 1. Daftar pertanyaan

\begin{tabular}{|l|l|}
\hline Segi SDM \\
\hline 1. & Apakah ada pekerja yang kurang ahli dan tidak menguasai pekerjaannya? \\
\hline 2. & Apakah para pekerja melakukan pekerjaan sesuai dengan prosedurnya? \\
\hline 3. & Kesalahan apa saja yang sering terjadi pada saat pekerja melakukan pekerjaannya? \\
\hline 4. & Apakah pengawas lapangan telah melakukan pengawasan yang benar? \\
\hline Segi Material \\
\hline 1. & Dari mana asal material yang digunakan? \\
\hline 2. & Apakah waktu tiba material pernah mengalami keterlambatan? \\
\hline 3. & Apakah supplier pernah melakukan pengiriman material yang salah? \\
\hline 4. & Bagaimana kualitas material yang digunakan? \\
\hline Segi Metode \\
\hline 1. & Apakah terdapat SOP dalam melakukan pekerjaan? \\
\hline 2. & Bagaimana proses pengendalian perkembangan proyek? \\
\hline 3. & Apakah Desain dari pembangunan telah dirancang dengan jelas? \\
\hline 4. & Apakah ada perhitungan yang jelas jumlah material yang dibutuhkan? \\
\hline Segi Lingkungan \\
\hline 1. & Apakah perlu melakukan proses awal sebelum mengolah tanah untuk melakukan pembangunan? \\
\hline 2. & Apakah tanah di Pasir puth mudah untuk di lakukan pembangunan? \\
\hline 3. & Apakah izin pembangunan pasir puth menjadi salah satu penghambat pembangunan? \\
\hline 4. & Apakah pembangunan akan terganggu jika hujan atau dalam keadaan cuaca yang tidak mendukung? \\
\hline Segi Mesin \\
\hline 1. Apa saja mesin yang dibutuhkan dalam pembangunan ini? \\
\hline 2. & Apakah mesin yang dibutuhkan telah tersedia dan cukup untuk melakukan proyek? \\
\hline 3. & Apakah mesin yang tersedia dapat berfungsi dengan maksimal? \\
\hline & Sumb \\
\hline
\end{tabular}

Sumber: Data Primer

\section{HASIL DAN PEMBAHASAN}

Hasil dari observasi yang dilakukan secara langsung pada lokasi penelitian adalah sebagai berikut: 


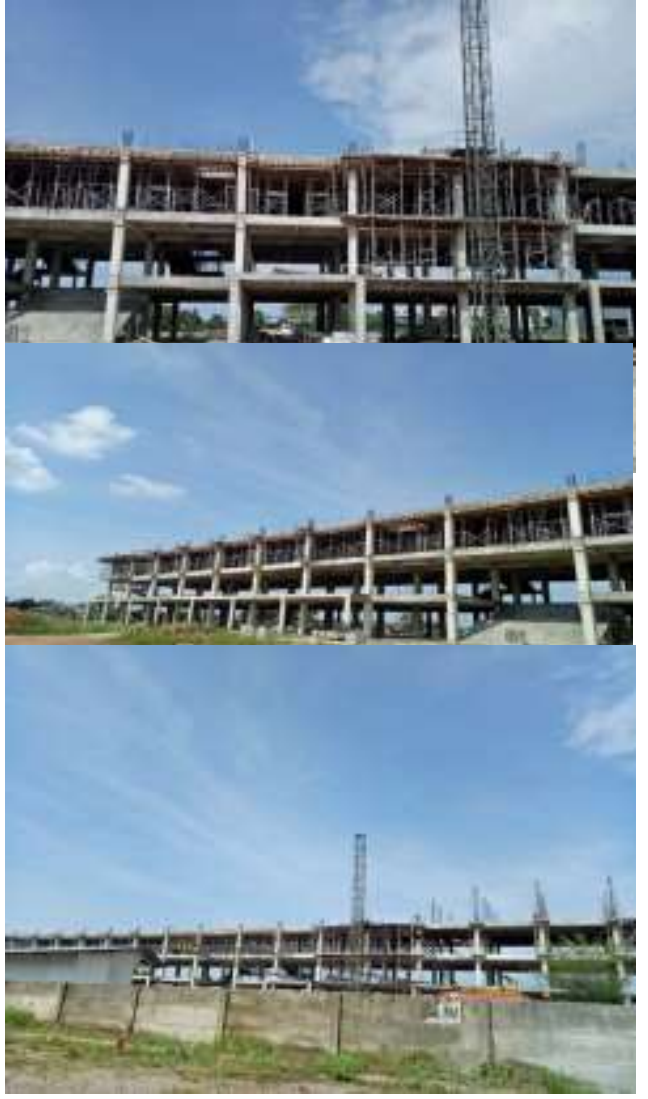

Gambar 2. Pembangunan UVERS

Universitas Universal (UVERS) merupakan universitas swasta di Kota Batam yang didirikan dengan Keputusan Menteri Pendidikan dan Kebudayaan Republik Indonesia No.601/E/O/2014. Universitas Universal (UVERS) berada dibawah naungan Yayasan Pancaran Maitri bersama dengan Sekolah Maitreyawira. Selam belasan tahun bergelut di dunia pendidikan dengan mendirikan Sekolah Maitreyawira dari tingkat TK, SD, SMP, hingga SMA dan SMK telah menginspirasi Yayasan Pancaran Maitri untuk membuat pendidikan yang lebih tinggi. Cita-cita tersebut diwujudkan dengan mendirikan Universitas Universal (UVERS, 2017).

Pembangunan Pasir Putih adalah sebuah proyek pembangunan Universitas yang bernama Universitas Universal.
Proyek ini dimulai pada tahun 2013, dengan 50 orang pekerja. Luas tanah Universitas ini adalah sekitar 4ha. Fasilitas yang akan dibangun adalah sebagai berikut:

1. Ruang Theater

2. Ruang Olahraga

3. Lapangan Sepak Bola dan Basket

4. Taman bunga

5. Café

6. Kantin mini

7. Supermarket mini

8. Hall Kebahagiaan (berkumpul santai)

Jumlah mahasiswa yang dapat ditampung dalam Universitas ini adalah sekitar 2500 orang Prediksi penyelesaian proyek ini adalah pada tahun 2023. Berdasarkan hasil wawancara dengan narasumber, didapatkan hasil jawaban sebagai berikut:

Tabel 2. Hasil Wawancara

\begin{tabular}{|c|c|}
\hline \multicolumn{2}{|r|}{ Segi SDM } \\
\hline 1 & $\begin{array}{l}\text { Iya, banyak sekali pekerja yang tidak } \\
\text { memiliki kelahlihan dalam melakukan } \\
\text { pekerjaan dan sering kali pekerja baru } \\
\text { belajar pada saat mulai melakukan proyek }\end{array}$ \\
\hline 2 & $\begin{array}{l}\text { Tidak, Pekerja tidak melakukan pekerjaan } \\
\text { sesuai urutannya sehingga sering kali } \\
\text { mengakibatkan kesalahan yang fatal }\end{array}$ \\
\hline 3 & $\begin{array}{l}\text { Pemeliharaan alat-alat yang digunakan, } \\
\text { kesalahan pemesanan material, kebocoran } \\
\text { atap }\end{array}$ \\
\hline 4 & $\begin{array}{l}\text { Ada kepala tukang tapi tidak memiliki } \\
\text { konsultan, tapi tukang dapat terkontrol } \\
\text { karena adanya pengawasan }\end{array}$ \\
\hline \multicolumn{2}{|r|}{ Segi Material } \\
\hline 1 & $\begin{array}{l}\text { Material didapatkan dari supplier dalam } \\
\text { Batam (Toko-toko perantara di Batam) }\end{array}$ \\
\hline 2 & Pernah tapi tidak sering \\
\hline 3 & $\begin{array}{l}\text { Pernah tapi tidak sering, mungkin terjadi } \\
\text { karena salah komunikasi }\end{array}$ \\
\hline 4 & $\begin{array}{l}\text { Berkualitas, karena pemilihan material } \\
\text { sesuai dengan permintaan dari pihak } \\
\text { UVERS }\end{array}$ \\
\hline \multicolumn{2}{|r|}{ Segi Metode } \\
\hline 1 & $\begin{array}{l}\text { Perencanaan kerja telah disepakati bersama } \\
\text { sebelum proyek di mulai, akan tetapi tidak }\end{array}$ \\
\hline
\end{tabular}


ada sebuah kerangka yang diberikan kepada tukang. Kepala tukang yang bertugas untuk memberitahukan pembagian dan perencanaan kerjanya kepada tukang. Sehingga mengakibatkan kesalahpahaman dan kesalahan

2 Proses pengendaliannya langsung dipercayakan kepada tukang, namun pembelian material atau keperluan tetap dipegang oleh yayasan tapi perhitungan jumlah keperluan berdasarkan pada permintaan tukang

3 Rancangan telah di rancang namun, akan berubah-rubah sesuai kondisi dan situasi

4 Perhitungan material yang dibutuhkan langsung dilakukan oleh tukang, sering kali terjadi kesalahan dalam perhitungan misalah kelebihan material karena di pesan berulang kali

\section{Segi Lingkungan}

1 Perlu melakukan penimbunan dan potong lahan, kedua proses menghabiskan waktu yang cukup lama

2 Mudah, sebelumnya perlu melakukan perataan

3 Izin pembangunan telah dikeluarkan sehingga pembangunan dapat dilakukan

4 Pada saat baru mulai pekerjaan akan terganggu, tapi saat ini pekerjaan mulai bertambah jika terjadi cuaca yang tidak mendukung tukang tetap dapat melakukan pekerjaan lain

\section{Segi Mesin}

1 Menyewa mesin jack hammer (untuk menghancurkan batu), mesin vibrator (mesin getar), mesin bending (pembengkok besi), Belco (perataan tanah), lift barang (untuk menaik turunkan material)

$2 \quad$ Cukup

3 Alat dan mesin dapat berfungsi namun, sering kali mengalami kerusakan karena kuranganya pemeliharaan dan kurangnya keahlian dalam penggunaanya

Sumber: Pengolahan Data

Jawaban-jawaban di olah dan di susun berdasarkan kategori komponen utama fishbone diagram (6M) dalam sebuah gambaran diagram batang, sehingga dapat mengetahui masalah yang harus diprioritaskan ataupun urutan permasalahan. Berikut ini adalah gambaran diagram batang:

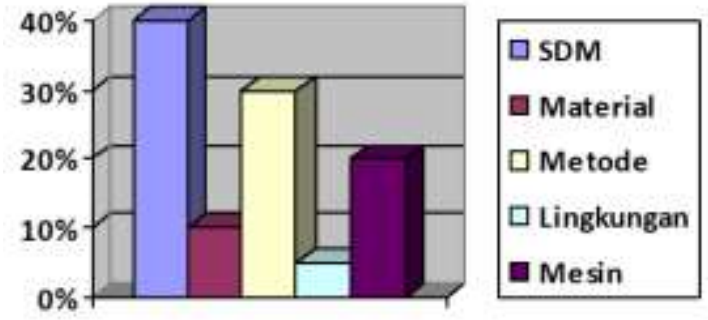

Gambar 3. Diagram Batang

Setelah mengetahui masalah yang diprioritaskan, maka perlu dilakukan perbaikan dengan. Namun sebelumnya setiap permasalahan yang telah dikategorikan perlu dijabarkan dengan jelas dengan metode Fishbone. Berikut adalah penjabaran masalah:

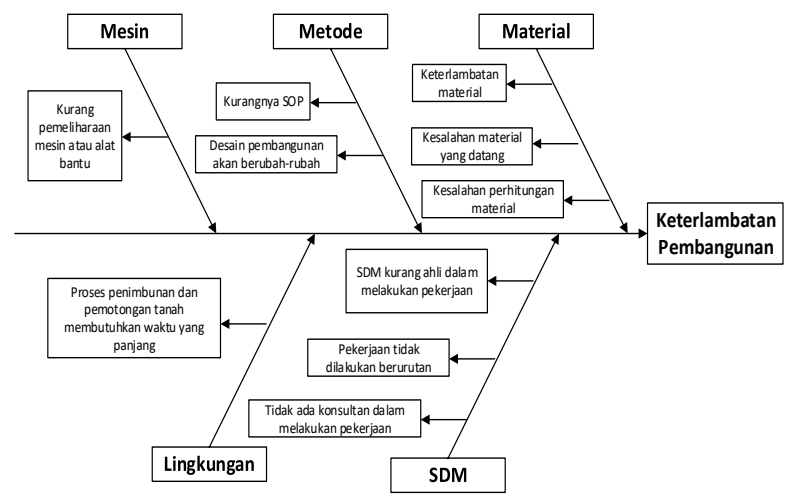

Gambar 4. Fishbone Diagram

Berdasarkan diagram di atas, terdapat 5 jenis faktor yang mempengaruhi proses pembangunan adalah dari segi SDM, material, metode, mesin, dan lingkungan. Masalah yang paling sering terjadi adalah kecerobahan SDM karena kurang skill dan tidak mengikuti prosedur pekerjaan sehingga hasil pekerjaan tidak maksimal bahkan terlambat. Hal tersebut dikarenakan oleh kesalahan-kesalahan yang sering terjadi pada proses pembangunan sehingga pekerjaan harus diulangi. Disamping itu pekerja yang melakukan pekerjaan tanpa konsultan sehingga pekerja sering kali melakukan dengan perencanaan sendiri 
sehingga akhirnya terjadi kesalahan dan kembali mengulangi pekerjaanya tersebut. Efek dari kesalahan akan menghabiskan waktu, material, listrik, hingga biaya.

\section{KESIMPULAN}

Berdasarkan hasil dari penelitian yang telah dilakukan terhadap proses pembangunan Universitas Universal terdapat beberapa jenis faktor-faktor yang menyebabkan keterlamabatan proses pembangunan adalah sebagai berikut:

1. Sumber Daya Manusia

2. Material yang digunakan

3. Lingkungan

4. Metode yang digunakan

5. Mesin yang digunakan

Setelah melakukan wawancara didapatkan bahwa faktor yang paling berpengaruh pada pembangunan tersebut adalah masalah sumber daya manusia. Hal ini disebabkan oleh kurangnya skill para pekerja sehingga hasil dari pekerjaan yang dilakukan tidak sesuai dengan ketentuan. Sering kali para pekerja bekerja tanpa mengikuti prosedur atau urutan pekerjaan. Selain itu faktor metode juga mempengaruhi proses pembangunan karena tidak memiliki SOP yang jelas sehingga urutan pekerjaan hanya diberitahukan secara lisan dan akan menyebabkan kesalahan yang tidak diinginkan dalam proses pembangunan.

Jika faktor-faktor yang menjadi keterlambatan ini tidak segera diberikan perbaikan maka akan muncul risikorisiko yang tidak diperhitungkan. Seperti terjadinya kecelakaan kerja, waktu pengerjaan yang lambat, dan hasil proyek yang tidak sesuai dengan harapan stakeholder dikarenakan yang menjadi faktor utama adalah sumber daya manusia.

\section{DAFTAR PUSTAKA}

Aulia, N. A. (2016). Analisis dan Evaluasi Sisa Material Konstruksi Menggunakan Diagram Pareto dan Fishbone Diagram pada Proyek Pembangunan Gedung Pascasarjana Universitas Islam Malang.

Ervianto I.W. (2016). Manajemen Proyek Konstruksi Penerbit, (November 2016), 2002.

I Made Alit Karyawan Salain, G. A. P. C. D., \& Anindita, G. N. (2019). Analisis Risiko Keterlambatan Pelaksanaan Proyek Konstruksi Hotel Di Bali. Spektran, 7(2), 212221.

Karunia, M. N. (2016). Analisis Risiko Keterlambatan Waktu Pada Proyek (Studi Kasus: Pembangunan Jalan Tol Trans Sumatera BakauheniTerbanggi Besar, 1-60.

Kusnadi, E. (2018). Fishbone Diagram dan Langkah-langkah Pembuatannya, 1-6.

Messah, Y. A., Widodo, T., \& Adoe, M. (2013). Kajian Penyebab Keterlambatan Pelaksanaan Proyek Konstuksi Gedung Di Kota Kupang. Jurnal Teknik Sipil, 2(2), 157-168168.

Nilma, N. (2018). Analisis Cause Effect Mengenai Dampak Dari Implementasi Bandung Smart City. Faktor Exacta, 11(1), 57. https://doi.org/10.30998/faktorexact a.v11i1.2315

Pamungkas, R. W. P., \& Khalida, R. (2019). Manajemen Proyek Agile dengan Pendekatan Metode Scrum 
sebagai Peningkatan Layanan Berkelanjutan Perusahaan, 187-194. Retrieved from http://seminar.iaii.or.id/index.php/SI SFOTEK/article/view/124

RI, P. (1999). Undang Undang Republik Indonesia No 18 Tahun 1999.

Risnu, R. (2016). Implementasi Otomatisasi Konstruksi Implementation of Construction Automation in Construction Industry of.

Rosanti, N., Setiawan, E., \& Ayuningtyas, A. (2016). Penggunaan Metode Jalur Kritis Pada Manajemen Proyek (Studi Kasus: Pt. Trend Communications International). Jurnal Teknologi, $8(1)$, 23. https://doi.org/10.24853/jurtek.8.1.2 3-30

Safrizal1, M. D., Rauzana, A., \& Muttaqin. (2019). Konstruksi Paling Dominan Di Kabupaten Aceh Utara Sumber data merupakan subyek dari mana data dapat diperoleh . Dalam. Teknik Sipil, 9(2), 145-152. https://doi.org/http://dx.doi.org/10.2 9103/tj.v9i2.210

Stephanie, S., \& Dinariana, D. (2016). Project Planning And Controlling Gedung Rusunawa Universitas Indonesia Dengan Ms.Project. Penelitian Dan Pengabdian Kepada Masyrakat, 4, 53-109.

Sugiyarto, Hartono, W., \& Prakoso, I. T. (2017). Analisis Dan Identifikasi Sisa Material Kontruksi Dalam Proyek Pembangunan Dan Peningkatan Jalan. Matriks Teknik Sipil, (September), 1070-1077.

Sugiyono. (2016). Metode Penelitian
Kuantitatif, Kualitatif dan R\&D. Bandung: PT Alfabet.

Syaputra, R. (2011). Analisa Resiko Proyek Pembangunan Universitas Islam Riau ( Studi Kasus: PT . Bumi Alam Mayang Permai ).

Tanjung, L. S. (2017). Pembangunan Air Bersih Dengan Menggunakan, 3(1), 38-45.

UVERS. (2017). Profil UVERS. Retrieved from http://uvers.ac.id/in/pages/profiluvers

Yusuf, A. (2014). Analisis Kebutuhan Pendidikan Masyarakat. Jurnal Penelitian Pendidikan, 31(2), 7784. https://doi.org/10.15294/jpp.v31i2.5 690 